Isenhardt, A., \& Hostettler, U. (2020).

Inmate Violence and Correctional Staff Burnout: The Role of Sense of Security, Gender, and Job Characteristics. Journal of Interpersonal Violence 35(1-2): 173207. https://doi.org/10.1177/0886260516681156

This is the authors' final accepted version.

There may be differences between this version and the published version. You are advised to consult the publisher's version if you wish to cite from it.

\title{
$\boldsymbol{u}^{b}$
}

b
UNIVERSITÄT
BERN

BORIS

Bern Open Repository and Information System

https://boris.unibe.ch/id/eprint/91199

Deposited on: 23 December 2019 
Isenhardt, A., \& Hostettler, U. (2020). Inmate Violence and Correctional Staff Burnout: The Role of Sense of Security, Gender, and Job Characteristics. Journal of Interpersonal Violence 35(1-2): 173-207. https://doi.org/10.1177/0886260516681156

\section{Inmate Violence and Correctional Staff Burnout: The Role of Sense of Security, Gender, and}

\section{Job Characteristics}

Anna Isenhardt \& Ueli Hostettler

University of Bern, Institute for Penal Law and Criminology

Anna Isenhardt https://orcid.org/0000-0001-6766-909X

Ueli Hostettler https://orcid.org/0000-0002-0331-4203

Abstract

Violence in the workplace has serious consequences for employees and organizations. Based on a survey in early 2012 among employees from all work areas of 89 of the total 112 correctional facilities in Switzerland resulting in a sample of 2,045 employees (response rate 48.5\%), this study (1) analyzed whether victimization has an impact on correctional staff burnout, (2) tested the hypothetical mediating role of sense of security in the relationship between victimization and burnout, and (3) included gender and job characteristics because work experiences and exposure to violence of staff differ strongly with gender and work tasks. Two different forms of violence were considered: (1) experienced violence (inmates-on-staff) and (2) observed violence (inmate-on-inmate). Analysis was carried out using structural equation modeling. Results show that victimization and witnessing violence between inmates negatively affects the personal sense of security and increases correctional staff burnout. In addition, the sense of security mediated the effect from experienced and observed violence on burnout. Gender and job characteristics also proved to be important. This is especially true for staff working as correctional officers, employees working with young inmates and with inmates awaiting trial who reported a greater exposure to violence and a lower sense of security. The study adds to the knowledge on violence and its outcomes in corrections and contributes to the literature on the consequences of workplace violence in general and, specifically, in social service occupations.

Keywords: inmate violence, burnout, sense of security, prison, staff, Switzerland 
Inmate Violence and Correctional Staff Burnout: The Role of Sense of Security, Gender, and Job Characteristics

\section{Introduction}

Very often, violence in the workplace entails serious consequences for employees (e.g., higher risk of burnout, lower organizational commitment) and the entire organization or enterprise (e.g., absenteeism, employee turnover; Lambert, Hogan, \& Altheimer, 2010b, 2010a; LeBlanc \& Kelloway, 2002; Spector, Coulter, Stockwell, \& Matz, 2007). In comparison to other occupations, correctional staff — much like in health care, social work, and law enforcement professions — have a higher risk of victimization (Bourbonnais, Jauvin, Dussault, \& Vézina, 2007; LeBlanc \& Kelloway, 2002). Next to bullying and violence by fellow staff members and supervisors, which can occur in every occupation, people in these professions must also expect violence from their clients. This is particularly true in corrections.

Corrections workplaces can, for many reasons, be seen as being prone to an increased risk for experiencing violence. Due to different forms of deprivations affecting inmates (Clemmer, 1940; Sykes, 1958; Toch, 1992) and inmate histories of aggressive behavior (Irwin \& Cressey, 1962), the atmosphere within correctional facilities is often characterized by a general state of tension. This may result in victimization of staff by inmates, in violence and victimization between inmates, and, when violence is observed by staff or other inmates, in indirect victimization. Although staff-on-inmate victimization occurs in corrections, of more interest here is how correctional staff well-being (burnout) and sense of security are affected by experienced and observed victimization. While this high risk is acknowledged, scientific work on the effects of interpersonal violence on correctional staff is largely missing.

\section{Correctional Staff Burnout}

Staff burnout is a consequence of work stress and stressful events in the workplace. It is generally described as a three-dimensional construct comprising of the dimensions (a) emotional exhaustion, which is accompanied by feelings of exhaustion, frustration, excessive demand, and reduced performance, (b) depersonalization, which is characterized by distancing oneself to ones clients 
and treating them with cynicism and indifference, and (c) a reduced sense of personal accomplishment (Maslach \& Jackson, 1981). A burnout can occur in every of these three dimensions separately, even though emotional exhaustion is often viewed as core dimension (Maslach, 2003). More recent studies showed that a reduced sense of personal accomplishment can be viewed as consequence of exhaustion and depersonalization, and not as a separate dimension of burnout.

The present study refers to burnout as a two dimensional concept containing the two dimensions exhaustion and disengagement by following Demerouti, Bakker, Vardakou, and Kantas (2003). In their definition exhaustion is not only reduced to affective aspects, but also includes physical and cognitive aspects, and disengagement covers negative attitudes towards work tasks and work objects and not only towards clients.

Correctional staff due to their care-orientated work tasks and their close contact with inmates may be considered at risk and several studies researched the factors influencing the development of burnout within this specific occupation. In their literature review Schaufeli and Peeters (2000) identified role problems, work overload, demanding social contacts (with supervisors, colleagues and inmates), and poor social status as major factors associated with burnout and job stress. A meta-analysis by Dowden and Tellier (2004) revealed similar results. Role conflict, role ambiguity and perceived job dangerousness had a negative effect on correctional officers work stress whereas participation in decision making and job satisfaction showed a positive effect. In comparison, demographic variables and job characteristics (e.g. security level) were the weakest correlates. Finney, Stergiopoulos, Hensel, Bonato, and Dewa (2013) confirmed these results and stated the importance of the organizational structure (e.g. participation, fair treatment, and organizational support), the social climate within the correctional institution and the relationship with supervisors.

\section{Consequences of Workplace Violence}

Few studies examined consequences of violence on the well-being of correctional staff. Their findings are divers. Whereas the effect on posttraumatic stress disorder (PTSD) is small (Boudoukha, Altintas, Rusinek, Fantini-Hauwel, \& Hautekeete, 2013) or could not be proven (Kunst, Schweizer, Bogaerts, \& van der Knaap, 2008), violence had a significant correlation with burnout (Boudoukha et 
al., 2013) and increased levels of stress (Bourbonnais et al., 2007; Steiner \& Wooldredge, 2015).

Other research showed evidence that a low sense of security and fear of victimization creates job stress, increases burnout, and reduces job satisfaction, organizational commitment, and perceived health (Blevins, Cullen, Frank, Sundt, \& Holmes, 2006; Brough \& Williams, 2007; Finn, 1998; Griffin, 2001; Lambert, Hogan, \& Griffin, 2007; Schaufeli \& Peeters, 2000, Isenhardt, Young \& Hostettler, 2016). When both factors were considered simultaneously, sense of security had a stronger impact than victimization (Finn, 1998; Steiner \& Wooldredge, 2015). Furthermore, studies conducted by Rogers and Kelloway (1997) and Schat and Kelloway $(2000,2003)$ in samples of bank tellers, hospital staff, and employees in health care settings showed that exposure to violence predicted the fear of future violence, and, in turn, fear of future violence predicted psychological well-being, somatic symptoms, the intent to leave the organization, and job neglect. In all samples, fear of future violence also appeared to have a mediating effect in the relationship between exposure to violence and personal and organizational outcomes.

A theoretical explanation for this mediation is offered by the assumptive world perspective (Janoff-Bulman \& Hanson Frieze, 1983). Victimization and threat lead to a disruption of the assumptive world of the individual, which involves a reduction of the perception of the world as meaningful, the view of the self as positive, and a change in the perception of personal invulnerability. Inadequate coping strategies can inhibit the reconstruction of meaningful personal beliefs about the world after victimization. Thus feelings of insecurity remain and cause stress, which is considered as a central factor for the development of burnout (Demerouti \& Bakker, 2008; Demerouti, Bakker, Vardakou, \& Kantas, 2003; Maslach, 2003; Maslach \& Jackson, 1981).

Likewise, a connection between exposure to violence and perceived safety has been detected in the correctional context. Lai, Wang, and Kellar (2012) showed for Taiwanese correctional staff that experiencing violence led to a lower perception of workplace safety. The same result was encountered for inmates (Wolff \& Shi, 2009, 2011).

\section{The Impact of Gender and Job Characteristics on Victimization}

Depending on their job characteristics and job tasks, employees differ in their exposure to 
violence (Bowker, 1980; LeBlanc \& Kelloway, 2002; Light, 1991). Corrections, in general, is a field with specific characteristics known to contribute to a greater exposure to violence (Chappel \& Di Martino, 2006; LeBlanc \& Kelloway, 2002). However, this exposure to violence also varies between employees of different areas within a correctional institution.

Bowker (1980) identified five types of risk of victimization for correctional staff. Among them, the most common is the "daily grind," consisting mainly of psychological forms of aggressive inmate behavior and "patterned spontaneous attacks," which occur during the execution of specific forms of daily work tasks. These work tasks are classified as high-risk activities, including escorting inmates to punitive segregation units or moving enraged inmates from one cell to another. In addition, Light (1991) analyzed disciplinary records and identified 11 situations in which assaults against correctional staff occurred. A majority of cases belong to a category of unexplained and rather spontaneous incidents. Other high-risk situations occur when officers command or order, when inmates protest against routine activity because they perceive them as unfair, when officers search inmates or cells, when inmates fight, when officers discipline inmates, and when inmates are emotionally unstable due to mental illness or upon reception of bad news from family or authorities.

In Switzerland, all situations described by Bowker (1980) and Light (1991) as carrying a particularly high risk of victimization encompass risks and work tasks that are associated with the work of front-line correctional officers who are supervising inmates and who are first-contact persons for most inmate needs. In most institutions, these employees also are those who must immediately respond in case of an escalation or emergency and who have to intervene in case of inmate fights. In line with these considerations, Spinaris, Denhof, and Kellaway (2012) found that correctional officers were more often victims of a so-called "VID" (violence, injury, death) event during their careers.

Work tasks and exposure to violence also differ by a range of inmate characteristics. A strong predictor for violent behavior of inmates during incarceration is inmate age. Several studies show that the younger the inmates are, the greater their probability for engagement in violence between inmates or against staff (Arbach-Lucioni, Martinez-García, \& Andrés-Pueyo, 2012; Camp, Gaes, Langan, \& Saylor, 2003; Kuanliang \& Sorensen, 2008; Lahm, 2009; Light, 1991; Steiner \& Wooldredge, 2008). 
In addition, it can be expected that facility type and function of the specific unit an employee works in plays a role. Inmates in prisons have been found to be more often engaged in a verbal or physical assault (James \& Glaze, 2006) and are more often sexually victimized (Beck, Berzofsky, Caspar, \& Krebs, 2013) than inmates in jails. Homicide is also more prevalent in prison than in jail (Mumola, 2005). In contrast, Arbach Lucioni et al. (2012) found for Spain, that being on remand is a risk factor for prison violence.

Also, gender influences the perception of risk and the sense of security. Due to a higher actual or perceived vulnerability, women often have a lower sense of security. This is well known from research on fear of crime (e.g., Hale, 1996) and was also shown for the correctional context (e.g., Gordon, Moriarty, \& Grant, 2003). In general, women tend to have a greater risk for different forms of workplace violence, like bullying or sexual harassment (Chappel \& Di Martino, 2006). In contrast, Spinaris et al. (2012) found that within corrections and when an inmate is the perpetrator, male employees were more often victimized than women.

Next to employees' gender also inmates' sex can influence staff exposure to violence. However, previous findings in this regard are mixed. Based on data for federal prisoners from the U.S., Harer and Langan (2001) found that women committed less prison violence and less serious forms of prison violence. Wolff, Blitz, Shi, Siegel \& Bachmann (2007) found no differences in the prevalence of inmate-on-inmate violence in thirteen adult men and one adult women prisons in a U.S. mid-Atlantic state. Isenhardt (in press) showed for the years 2011, 2012 and 2013 that the overall levels of violence in the two Swiss prisons housing female prisoners with sentences longer than one year were higher compared to male prisons.

\section{The Current Study and Hypothesis}

The current study is part of a larger research project that aims to better understand the situation and well-being of correctional staff in Switzerland (Isenhardt, Hostettler, \& Young, 2014). It takes stock of previous research showing that workplace violence is associated with different forms of negative consequences for the employees and the organization. This association has been found to be mediated by fear of future victimization in different occupations, but has not yet been tested within the context 
of corrections (LeBlanc \& Kelloway, 2002; Rogers \& Kelloway, 1997; Schat \& Kelloway, 2000). In addition, it seems reasonable to assume that employees of different areas of correctional institutions differ in their exposure to violence and in their sense of security because of the differences in their work tasks.

Institutional and inmate population characteristics also contribute to differences in the work environment. Inmate age, for example, influences the overall level of violence and therefore the risk of victimization for staff. Differences between staff working with adjudicated inmates and staff working with inmates awaiting trial, and inmate sex are also hypothesized to play a role. Due to the specific daily routine and conditions in units where pre-trial detention or detention to ensure deportation is applied, it can be expected that also in Switzerland violence is more frequent in units housing adjudicated prisoners. Inmates awaiting trial are mostly held in solitary confinement. This reduces the possibilities for contact with other inmates, and therefore, also opportunities for conflicts with other inmates are limited when compared to units for adjudicated inmates where frequent and intensive inmate-to-inmate contact is often part of the rehabilitative concept. In addition, findings for Switzerland (Isenhardt, in press) show that the risk of inmate-to-staff victimization and inmate-on-inmate victimization is higher in institutions for female offenders, where, compared to institutions for male inmates, the overall rate of violence is slightly higher.

Previous studies in corrections considered violence and sense of security only as separate factors and neglected the role of potential mediating factors. Furthermore, they did not address differences of work characteristics and personal background of employees. By contrast, our research focuses on (a) a possible mediating effect of sense of security in the relationship between violence and burnout, (b) differences in job characteristics and gender, and (c) in addition on experienced violence by staff, observed victimization through witnessing violence between inmates and a possible connection between these two forms of violence.

Based on these considerations, we formulated the following hypotheses (see, for a graphic representation, Figure 1). First, we hypothesized that experienced and observed victimization have a direct effect and increase the risk of burnout for correctional staff. Second, it is assumed that sense of 
security has a mediating role in these relationships and staff members who have been victimized or have observed violence between inmates have a lower sense of security, which in turn increases the risk of burnout. Therefore, both forms of violence have, next to the direct effect mentioned in hypothesis one, an additional indirect effect on burnout via sense of security. Third, female staff members are less often victimized by an inmate and observe as much violence between inmates as male staff members, but have a lower sense of security. Fourth, staff working with young offenders, in an unit for adjudicated inmates, with female inmates, and as frontline correctional officers, are involved in more incidents of experienced and observed violence. Fifth, because of the higher exposure to violence, staff working with young offenders, in prison, with female inmates, and as frontline correctional officers, feel less safe and experience an increase of burnout. Sixth, observing violence between inmates increases the risk of victimization of staff members.

In addition, this study controlled for the direct effects of differences in gender and job characteristics (e.g., institutional characteristics, different work tasks, and inmate age) on burnout.

\section{Method}

The research project, of which this study is a part, deals with different questions of prison staff well-being and work performance. For this, a cross sectional study was conducted in Swiss correctional facilities in all regions of the country. This was the first national survey on work conditions, working atmosphere, job satisfaction, interactions with inmates, workload, and attitudes toward central themes of the penitentiary system among correctional staff in Switzerland (Isenhardt et al., 2014; Hostettler \& Isenhardt, 2015). At the time of the study in early 2012, Switzerland counted 112 correctional facilities, of which 89 participated in the study. The requests for participation were either made directly at facility level or, when existent and suitable, at the level of relevant cantonal authorities. ${ }^{1}$ Research was endorsed by the Conference of Cantonal Justice and Police Directors, the Swiss Prison Staff Training Center, and the Association of Swiss Prison Governors.

At the time of the survey, these 89 facilities employed a total of 4,217 persons. All of them were provided with a questionnaire and a cover letter with information about the purpose of the study and the voluntariness of participation. ${ }^{2}$ The distribution was organized via the facilities and performed 
by the prison governors, direct supervisors, or by placing them into the individual mail box of each employee. Completed questionnaires were all directly and anonymously sent to the research team by means of an enclosed pre-stamped and addressed envelope.

From three small participating facilities, one prison hospital (14 employees), a center for sociotherapy (6 employees) and a jail (40 employees), no employee questionnaires were received. This reduces the number of facilities, from which employee responses were gathered to 86. Among these, 47 facilities are jails for pre-trial detention, short sentences with a maximum length of one year, and administrative detention for foreign nationals held for deportation. Furthermore, the institutional sample contained two forensic psychiatric hospitals, one prison hospital, eight facilities for juvenile offenders, and five special homes for release preparation of inmates who approach the end of sentence. ${ }^{3}$ The size of facilities varied strongly between the smallest with an intake capacity of only five inmates and the largest with a capacity for 425 . The minimum number of employees per facility was three, and the maximum number was 314 . The response rate was $48.5 \%$, which is comparable to other studies in similar correctional systems and with similar study designs (e.g., Lehmann \& Greve, 2006).

\section{Sample}

The sample includes 2,045 employees from all work areas of the correctional facilities (except prison governors) and from all regions of Switzerland. Overall, $75.3 \%$ of the respondents spoke German, $22.0 \%$ French, and 2.7\% Italian. With regard to working roles, $41 \%$ worked as correctional officers, who are responsible for general inmate surveillance, support and in many institutions also for security issues. In other facilities a number of specialized security staff is employed. They take care of all security issues like entry control, video surveillance, cell search and emergency interventions and represent $9.4 \%$ of the total sample. As industry staff, who supervise and instruct the prisoners within the different areas of mandatory prison labor worked $18.8 \%$ of the total sample. Another $9.2 \%$ worked in administration, $7.4 \%$ as treatment staff (including psychologists, psychiatrists, and social services), $3.5 \%$ as medical staff, $3 \%$ as educational staff, and $7.7 \%$ worked in other areas, such as technical service, food service, or in pastoral care. Most of the participants were male (566 women, 1,469 men, 10 unreported) and between 31 und 60 years old (22.2\% 31-40 years, $34.5 \% 41-50$ years, and $28.7 \%$ 
$51-60$ years).

Overall, $53.1 \%$ reported some kind of vocational training as their highest education, $17.5 \%$ hold a university degree, and $11.8 \%$ completed a higher degree in vocational training. For tenure, the highest proportion was between one year and five years (28.5\%), 20.3\% worked between six and 10 years within a correctional facility, $25.2 \%$ between 10 and 20 years, and $14.5 \%$ more than 20 years. The majority were employed in facilities for the execution of sentences and measures (62\%), both types house adjudicated inmates. Another big group worked in a jail, where inmates in pre-trial detention, administrative detention, and with short sentences, usually up to a maximum of one year, are placed $(28.8 \%)$.

With regard to security level, in Switzerland the distinction between medium and high security is not always clear. Medium security facilities may have high security units, which mainly houses new inmates before transferring them to the medium security part of the prison and high security facilities may have medium security units which mainly house inmates who approach the end of their sentence. This is due to the number of relatively small facilities encompassing both regimes where employees of a single facility can work in units with different security levels. The majority in the sample (53.3\%) worked in a high security unit, $21.23 \%$ in a medium security unit and $24.3 \%$ in a medium and a high security unit. ${ }^{4}$

For several reasons, for the actual study, the sample size was reduced from 2,045 to 2,026 in the confirmatory factor analysis and to 1,974 in the full structural model. The first reason relates to the filtering procedures in the questionnaire. If an employee stated that he or she had no contact with inmates during the last six months before the questionnaires were distributed, all questions which require staff-inmate interactions, such as victimization by an inmate or witnessing violence between inmates, were excluded. This filter question was applied because our sample contains employees out of all possible work areas including mere administrative staff without any contact with inmates. Whereas most of the administrative staff also had contact with inmates, about $2.9 \%$ of the total sample did not (55 employees). The second reason is missing values in one or more of the studied variables or the cluster variable, which further reduces the sample size. 


\section{Analysis Strategy}

Data have been analyzed using structural equation modeling. As a first step, the quality of the measurement model was explored, using Confirmatory Factor Analysis (CFA). Within this analysis, all three latent constructs used were analyzed at the same time to detect potential crossloadings and error correlations. The measurement model was fitted by looking at global fit measures (namely $\mathrm{X}^{2}, \mathrm{CFI}$, TLI, RMSEA, and SRMR), factor loadings, composite reliabilities and intra and inter factor correlations of items. After that descriptives of and correlations between all studied variables have been viewed. In the last step, the structural model was constructed by relating the variables to one another. All hypotheses were tested using one single model, which already included all variables representing gender and job characteristics. This is an advantage since the model parameters have been estimated under control of these differences. In addition, indirect effects have been calculated and tested for significance. In this way, it was possible to test whether sense of security has a mediating role and how big the size of the effect of experienced and observed violence via sense of security is. Furthermore, it was possible to assess, if, for instance, the assumed higher exposure to violence for employees who work with young offenders, with adjudicated inmates or as correctional officers, also leads to a lower sense of security and an increase in burnout.

The analyses were conducted with Mplus 7.2 (Muthén \& Muthén, 2015). To avoid problems with multivariate non-normality, the Robust Maximum Likelihood (MLR) estimator was used because both forms of violence are not normally distributed. The numbers of employees who experienced or observed violence are rather low. Thus, in addition to conventional significance levels also significances on the ten percent level are reported.

Because survey participants are clustered in institutions, observations cannot be expected to be independent from each other. This is also indicated by Intraclass Correlation (ICC) values up to 0.15 , which can be considered as rather high (Hox, 2010, p. 244). As a consequence, the standard errors have been corrected to avoid bias and to control for the clustering effect (Muthén \& Muthén, 2015).

\section{Measures}

\section{Latent Factors}




\section{Burnout}

To measure Burnout, the German version of the Oldenburg Burnout Inventory (OLBI) was used for this study and was also translated into French and Italian. According to the definition of burnout as multi- or bi-dimensional construct presented in the introduction, the OLBI measures the two core dimensions of burnout: exhaustion and disengagement. For each of the two dimensions eight items were formulated (Demerouti et al., 2003). Exhaustion is defined as a consequence of intense psychological and physical strain and understood as a long-term consequence of the exposure to certain job demands, such as feelings of insecurity during work. Sample items are, "After work, I tend to need more time than in the past in order to relax and feel better," or "I can tolerate the pressure of my work very well" (R). The disengagement subscale measures the distancing of oneself from one's work in general, work object, or work content, using statements like, "Lately, I tend to think less at work and do my job almost mechanically," or "I always find new and interesting aspects in my work" (R). A disengaged employee sees his or her work as no longer challenging, boring, or even disgusting. All items were rated on a 4point Likert-type scale ranging from 1 (strongly disagree) to 4 (strongly agree).

The two factor structure of the OLBI could be verified for different occupations (e.g., Demerouti et al., 2003; Demerouti, Mostert \& Bakker., 2010) and was successfully validated by using a longstanding instrument for the measurement of burnout, the Maslach Burnout Inventory (Maslach \& Jackson, 1981; Demerouti et al. 2003).

However, in this study confirmatory factor analysis revealed several problems with the structure of the burnout subscales. Overall fit indices imply a rather bad fit and the modification indices indicated that in both subscales one item each showed high crossloadings and rather low factor loadings on their assigned factors (see Table 1; for further information on the items and their wordings, see Demerouti et al., 2010, p. 222). To increase unidimensionality and discriminant validity and establish the two factor structure of the original scale the two crossloading-items were removed, which increases also the overall fit of the model (see modified Model 1 in Table 1). Nevertheless, two other items did not correlate highly with the other items of their assigned factor and have low factor loadings less than .40 . After deleting also these two items, overall fit indices showed finally an adequate model fit (see modified 
Model 2 in Table 1) with $\mathrm{X}^{2}=603.541(\mathrm{df} 87, \mathrm{p} .001), \mathrm{CFI}=.95, \mathrm{TLI}=.93, \mathrm{RMSEA}=.05, \mathrm{SRMR}=.04(\mathrm{Hu}$ \& Bentler, 1999). This final measurement model, which contains six items for exhaustion and six items for disengagement instead of the original eight items per subscale is used for all further analysis. ${ }^{5}$

Despite these modifications, the subscales can still be regarded as valid measures of exhaustion and disengagement. First, the remaining 12 items show high indicator reliability with factor loadings above .40. Second, the composite reliability measure (CR; Raykov, 1997, 2012), showed good internal consistency for exhaustion $(\mathrm{CR}=.83)$ and disengagement $(\mathrm{CR}=.78)$. In general, $\mathrm{CR}$ values higher than .60 are desirable as they indicate a high reliability of a given scale (Bagozzi \& Yi, 1988). Third, in their wording, removed items have no central relevance for the content related meaning of exhaustion and disengagement and could therefore be removed without affecting the overall meaning of the constructs. Fourth, the remaining items showed correlations well above .20 with the other items of the same factor. Fifth, in comparison correlations of items between the exhaustion and disengagement scales are smaller, so that exhaustion and disengagement can be viewed as distinguishable constructs.

\section{Sense of Security}

The measure of sense of security has been developed by the authors of the study to measure the personal feelings of security or insecurity while at work and the perceived overall level of security within the facilities. To measure these personal assumptions, the three following statements were combined into one factor: "I feel safe while working," "In general, the atmosphere in this facility is relaxed," and "The security in this facility is good." The items were rated on a 5-point Likert-type scale ranging from 1 (not true) to 5 (very true). The composite reliability measure $(\mathrm{CR}=.69)$ indicated an adequate internal consistency of these three items and intra factor correlations of items are all above .20 indicating also a good content validity (see Table 1). Factor loadings above .50 further indicate that these three indicators of sense of security belong to the same factor. Correlations between the items of the sense of security scale and items of disengagement and exhaustion are rather small, hence discriminant validity is given.

\section{Experienced Victimization}


To measure experienced violence of staff due to a victimization by inmates, a scale with five different forms of inmate aggressive behavior against staff has been constructed: (1) inmates have insulted me, (2) inmates have intimidated me verbally, (3) inmates have grabbed or held me, (4) inmates have assaulted me without a weapon, and (5) inmates have assaulted me with a weapon. Participants were asked to report how often they have been victims of these types of inmates' aggressive behavior during the last six months prior to the date of the survey. The response scale allowed for distinguishing between seven different frequencies of occurrence, ranging from 0 (never) to 7 (every day). Because the range of victimization varies in quality, a weighted mean score was built by weighting each form of inmate violence against staff according to their list position. Positive answers to "Inmates have insulted me" were given the factor one whereas those for "Inmates have intimidated me verbally" were given the factor two because it was assumed, an intimidation has the potential to be twice as much traumatic in comparison to an insult and so forth.

\section{Observed Victimization}

Observed violence, referring to the observation of violence between inmates, has been measured in a similar way. The list of aggressive behavior between inmates comprised: (1) verbal aggression, (2) assaults without injury of one or more inmates, (4) assaults with injury of one or more inmates, (4) sexual assault, and (5) assault with use of weapons. Like for experienced violence, respondents were asked to report on a 7-point scale how often they have observed one or more forms of aggression between inmates during the last six months prior to the date of the survey. Again, a weighted mean score was constructed according to the list position of each form of violence between inmates.

Table 2 shows that only a few employees reported incidents of experienced or observed violence, and when they did, such instances were reported has happening only up to once per week during the six months before the survey. This is why indices were built. Table 2 also shows that violence in Swiss prisons is mainly psychological. However, it should be kept in mind that the six months' time span for reporting is a rather closely defined period of time. 


\section{Gender and Workplace Differences}

All gender and workplace differences variables were measured and used on the individual employee level because within a single institution the workplace environments can be different for employees. Especially in jails, the inmate population is heterogeneous. This is due to the fact that Switzerland is a small country and the cantons are responsible for the execution of all different kinds of detention. Most cantons are too small to have the ability to provide infrastructure for all different kinds of detention they have to provide in separate facilities. This is why some facilities perform many different kinds of detention in one and the same facility, but in different units. ${ }^{6}$ Therefore, when different categories of inmates are housed in different units, one and the same facility can house adjudicated inmates, those who are in pre-trial detention, in detention awaiting deportation and those who were sentenced to a therapeutic measure, male and female inmates and juvenile and adult inmates.

The measurement of the inmate age segments was realized by using three dichotomous variables (inmates aged less than 18, inmates aged between 18 and 25, and inmates aged more than 25). Multiple answers were possible because an employee may work only with one age group or with more than one age group within the same institution. Out of the three dichotomous variables, a new dichotomous variable was built. For this, all employees who only work with inmates younger than 25 have been coded as 1 and all employees who work also with adult inmates as 0 .

Differences in work tasks were measured by asking employees about their specific position, whereby different answering options were provided, including correctional officers, industry staff, security staff, administration, social services, psychological services, medical staff, pastoral care and educational staff. Out of this the three dummy variables correctional officer, security staff and industry staff were created, using an aggregation of special services (social services, psychological services, medical staff, pastoral care and educational staff), administrative and other staff as reference category, because their work tasks and inmate contact is quite different from the inmate contact of correctional, industry and security staff, who work with inmates on a daily base.

To acknowledge differences in the function of the units, in a first step, different dummy variables representing all possible forms of detention (execution of sentences, execution of measures, 
pre-trial detention, custody pending deportation, specialized residential home for inmates who approach the end of their sentence, and forensic psychiatry) have been created. However, only differences between working in pre-trial detention or custody pending deportation and working in any other form of detention has shown to be relevant. Thus, they were merged to one dummy variable summarizing all forms of working solely with adjudicated inmates. A second dummy variable contains employees who work solely with pre-trial detainees and/or with inmates awaiting deportation. Working with adjudicated inmates and with inmates awaiting trial or deportation is used as reference category. ${ }^{7}$

Employee sex is also used as a dummy variable, where females were coded as 1 and males were coded as 0 . Inmate sex was measured threefold, providing working with male, female or inmates of both sexes as answering options. Again dummy variables were built and working with male inmates used as the reference category.

\section{Results}

\section{Descriptives and Correlations}

Before testing the hypothesized model, descriptive and correlational statistics for all study variables have been performed to get an idea about the distribution of the exogenous and endogenous variables (see Table 3). To improve interpretability, the means of the sum of indicators of sense of security, exhaustion, and disengagement are presented. The sample means for both exhaustion $(\mathrm{M}=2.24$; $\mathrm{SD}=0.62)$ and disengagement $(1.90 ; \mathrm{SD}=0.53)$ are below the neutral mean, which is set to 2.50 on the four-point answering scale. In comparison to exhaustion, the overall level of disengagement is even lower. Thus, most employees in Swiss corrections only suffer from a moderate level of burnout. Sense of security can be viewed as rather high, with a sample mean of $3.96(\mathrm{SD}=0.71)$, referring to the fivepoint answering scale. The weighted mean score for experienced violence has a mean of $0.04(\mathrm{SD}=0.18)$ and the weighted mean score for observed violence has a mean score of $0.07(\mathrm{SD}=0.26)$.

Gender and job characteristic variables are all dichotomous. Therefore, their mean also represents the proportion of employees who are associated with the job characteristic in question. With a proportion of $14 \%$, the minority of participants worked only with inmates aged less than 25 . About $28 \%$ of the officers are female and $41 \%$ worked as frontline correctional officers, $9 \%$ as security staff, and $19 \%$ as 
industry staff. The majority of them, $65 \%$ worked solely with already adjudicated inmates, another $12 \%$ solely with inmates awaiting trial or deportation.

Most of the job characteristics variables correlated to different degrees significantly with the mean scores of the endogenous variables. This indicates that they can contribute to explain the differences in employees' exposure to violence, sense of security, and burnout.

Furthermore, the correlations indicate that the study participants differ in their work characteristics by gender. More female employees worked in institutions for young offenders and more male employees as correctional officers. The proportion of women is higher in social services and education compared to any other position (Isenhardt et al., 2014; Isenhardt, Young, \& Hostettler, 2016).

\section{Influence of Victimization on Staff Burnout and the Mediating Role of Sense of Security}

The following two sections deal with the results of the full structural model (see Figure 1) and the related indirect effects. Whereas the first section explores the proposed influence of victimization on burnout and the role of sense of security in this relationship, the second section deals with the meaning of gender and job characteristic differences.

Overall, global fit measures indicate that the model fits the data $\left(X^{2}(219)=883.91, p<.001\right.$, $\mathrm{CFI}=.93, \mathrm{TLI}=.90, \mathrm{RMSEA}=.04, \mathrm{SRMR}=.03$ ). Results of the parameter estimation show (see Figure 1) that experienced and observed violence are connected. Observing violence leads to experienced violence $(\beta=.325, \mathrm{p}=.001)$. In addition, more frequent experienced $(\beta=.054, \mathrm{p}=.028)$ violence increases exhaustion. Disengagement is not directly influenced by either form of violence (nonsignificant paths). A low sense of security significantly increases both the level of exhaustion $(\beta=-$ $.457, \mathrm{p}=.000)$ and disengagement $(\beta=-.546, \mathrm{p}=.000)$. A comparison of the standardized parameter estimates revealed that sense of security is also the most important influencing factor within the model.

Experienced and observed violence also predicted sense of security. The negative sign of the parameter estimates indicates that the less frequently an employee experienced or observed violence between inmates and the less serious the incident, the higher is the subjective sense of security. In comparison to observed violence $(\beta=-.188 p=.000)$, the effect size of experienced violence $(\beta=$ $-.081, \mathrm{p}=.002)$ is smaller. 
Indirect and total effects have been conducted using the parameter estimates from the full structural model in order to examine the supposed influences from experienced and observed violence via a sense of security on both burnout subscales (see Figure 1). Table 4 shows that via sense of security all indirect effects are significant. Therefore, sense of security appears to be a mediator in the relationship between victimization and correctional staff burnout. For disengagement, the direct effects of both forms of violence are non-significant, and all indirect effects are significant. Therefore, it can be deemed that the relationships between experienced and observed violence and disengagement are fully mediated by sense of security and by experienced violence and sense of security, but not by experienced violence. The same is true for the effect from observed violence on exhaustion where only the indirect effects via sense of security and experienced violence has shown to be significant, whereas the direct effect is non-significant.

The relationship between experienced violence and exhaustion is partially mediated by sense of security. Both direct and indirect paths are significant.

\section{The Meaning of Gender and Job Characteristics}

Figure 1 also shows that in general gender and job characteristics can contribute to the explanation of differences in correctional staff exposure to violence and sense of security.

Sex had no significant influence on employees' exposure to experience violence, but male employees reported to have observed more often violence between inmates. The sense of security is also affected by gender. But, contrary to our hypothesis, female staff members felt safer than their male colleagues

In comparison to working with already adjudicated inmates and inmates in pre-trial detention, working only with inmates awaiting trial or deportation increases the risk of observing violence between inmates. To the contrary, employees who worked with adjudicated inmates were less often victimized by an inmate and less often observed violence between inmates. They also felt safer compared to their colleagues who worked not only with adjudicated but also with inmates awaiting trial or deportation.

As hypothesized, correctional officers reported more often to have observed violence and therefore had a higher exposure to violence. They also felt less safe compared to their colleagues with other duties (e.g., social, psychological, or medical services; education; security staff; and industry 
staff). The differences in feeling safe can be partly explained by higher exposure to violence of these employees. The indirect effects via observed violence and via observed violence and experienced violence are significant (see Table 5). In addition, inmates' age has an effect, but only on observed violence. The direct effect of working with inmates under the age of 25 on sense of security is also significant and negative. This indicates a lower sense of security for these employees. As Table 5 shows, there is also an indirect effect via observed violence and via observed and experienced violence.

Staff working solely with female inmates reported to have observed more often violence between inmates compared to their colleagues who work only with male inmates. The significance and negative sign of the indirect effect also indicates that mediated by observed violence the sense of security is affected by this higher exposure to observe violence.

Furthermore, gender differences and differences in job characteristics can-directly and mediated by sense of security, as well as experienced and observed violence—increase exhaustion and disengagement (see Figure 2 and Table 5). Therefore, being a female worker increases the exhaustion. This, however, does not seem to be linked to experienced or observed violence. Instead, the negative sign of the indirect effects from female to exhaustion via sense of security and via observed violence indicates that the exhaustion is decreased.

The direct path from correctional officers to exhaustion is negative. Thus, correctional officers have a lower risk for exhaustion than their colleagues in other positions. Indirect effects show the opposite effect. Being a correctional officer-mediated by observed violence, and by observed as well as experienced violence in combination with sense of security-leads to an increase in exhaustion. Disengagement is also increased when mediated by observed violence in association with sense of security. Working as security staff also led to a lower level of exhaustion. Because all indirect effects are non-significant, this cannot be explained by a difference in exposure to violence or differences in sense of security.

In general, the direct effects for staff working with inmates under the age of 25 indicated a lower risk of disengagement and exhaustion in comparison to their colleagues, who work also or only work with adult inmates. Indirect effects show that the total effect from working with inmates under the 
age of 25 on exhaustion and disengagement is also mediated by violence and sense of security. The opposite algebraic signs of the indirect effects compared to the direct effect show that also working with younger inmates can increase disengagement and exhaustion, when this is mediated by experienced violence, observed violence, and/or by sense of security.

Working solely with female inmates is associated with an increase in exhaustion, but with a decrease in disengagement. Indirect effects via sense of security or either form of violence are nonsignificant. Thus, the differences in the levels of exhaustion and disengagement between staff working with female and staff working with male inmates do not seem to be related to differences in their exposure to violence or sense of security.

\section{Discussion}

The purpose of the current study was threefold. First, we analyzed whether victimization has an impact on correctional staff burnout in Switzerland. Second, the hypothetical mediating role of sense of security in the relationship between victimization and burnout was tested. Third, because work experiences of staff within correctional facilities differ strongly with gender, exposure to violence, and work tasks, we examined gender and job characteristics. In our study, we considered two different forms of violence. First, we looked at the violence of inmates against staff (experienced violence) and, second, at violence observed between inmates (observed violence).

The frequency analysis showed that, with only three cases during the period of six months prior to the survey, inmate assaults on staff are almost non-existent and that violence against staff in Swiss correctional facilities is rather psychological in nature. These findings are in line with those in previous studies in other countries (Bowker, 1980; Rasmussen, Hogh, \& Andersen, 2013; Snacken, 2005). The same applies to violence between inmates, where serious verbal disputes also have been observed more often than physical assaults. In addition, both forms of violence occurred infrequently. Possible explanations for this may be attributed to Switzerland's relatively liberal prison conditions and the rather small size of facilities when compared to other countries. Furthermore, because the inquired time period was narrowly defined in the survey, reported numbers refer only to the six months prior to the study, and other incidents happening before have not been recorded. It is therefore unclear whether the 
defined period is representative or whether during this time the rate of violence was particularly low.

Despite the small number of employees who experienced violence at work, results showed that both forms of violence — experienced as well as observed —increased — at least indirectly — correctional staff members' exhaustion and disengagement. They also decrease the staff's sense of security, a result that is in line with the findings of Lay et al. (2012) on correction staff in Taiwan. Furthermore, the sense of security predicts burnout and, compared to violence, sense of security is a much stronger predictor for burnout. These findings also confirm those of earlier studies (Bourbonnais et al., 2007; Wooldredge $\&$ Steiner, 2015). In addition, experienced and observed violence are connected, and observing violence between inmates increased the risk for correctional staff of becoming a victim of inmate violence. A reason for this result can be found in the increased risk of victimization when breaking up inmate fights, as has been reported by Light (1991).

The analysis revealed that the effect of experienced and observed violence is mediated by sense of security. For the relationship between experienced violence and disengagement and the relationship between observed violence and disengagement, the analysis indicates a full mediation. Therefore, correctional staff level of disengagement is only affected by either form of violence, when thereby the sense of security is affected. Exhaustion is directly influenced by experienced violence. The sense of security does not necessarily need to be affected. For observed violence, only the indirect effects are significant.

Thus, the results obtained by Rogers and Kelloway (1997) and Schat and Kelloway (2000, 2003 ) indicating that fear has a mediating effect could be confirmed within our sample of correctional staff in Switzerland. Even though Rogers and Kelloway (1997) and Schat and Kelloway (2000) used fear of future victimization as mediating variable - whereas in this study we applied a more general measure of feeling safe within the institution and while at work-both measures represent feelings of security, which allows us to compare findings.

Because in our sample minor forms of experienced violence (mainly insults, intimidation, and touching) are rather overrepresented, we conclude that not only serious major incidents, but also the daily grind (Bowker, 1980), have an effect. This has also been observed in other studies with other 
occupations (Barling, Rogers, \& Kelloway, 2001) and with college students (Losavio et al., 2011).

The examination of gender and job characteristics revealed mixed results. The assumption that male staff members have a greater risk of experiencing violence could not entirely be confirmed. Male and female employees do not differ in their rate of experiencing violence by inmates, but male staff reported slightly more often to have observed violence between inmates. However, this difference could be explained by the higher proportion of male employees in correctional facilities and within our sample, which increases the chance that an employee who has observed violence between inmates is male. In addition, and contrary to our hypothesis, female staff members do not feel less safe than male staff members. Therefore, we conclude that female employees in Swiss corrections do not feel more vulnerable than male employees, and, although women had a higher risk of exhaustion compared to men, this is not related to violence.

Regarding our hypothesis that working with young offenders increases the risk of experiencing and observing violence, which both lead to a lower sense of security, results show for observed violence the proposed effect, but this is not the case for experienced violence. Employees working with inmates of this age group reported more often that they had observed violence between inmates, but were not more often victimized by an inmate. These results confirm partly those of several other studies, proving that age is a strong predictor for prison violence (Arbach-Lucioni et al., 2012; Kuanliang \& Sorensen, 2008; Kuanliang, Sorensen, \& Cunningham, 2008; Steiner \& Wooldredge, 2008). In addition, employees working with young offenders felt less safe, which can be partly explained by their higher exposure to observing violence between inmates. This also contributes to an increase in the risk of burnout. Positions also showed in part the proposed effect on violence. Frontline correctional officers reported more often having observed violence between inmates, but not having experienced more violence by inmates. They also felt less safe in comparison to their colleagues in other positions, such as social, psychological, or medical services and administrative staff. This is related to their greater exposure to violence. Working in security service or in prison industry does not have an effect on both forms of violence or sense of security. Overall, results revealed that frontline correctional officer had a lower level of exhaustion and disengagement, but, compared to employees in other positions, indirect 
effects showed that experiencing violence could mediate the effect for correctional officers on exhaustion and as a consequence increase the risk of being exhausted. Observed violence also plays a role when it affects the sense of security. This is rooted in the fact that correctional officers have the most intensive inmate contact, which explains their higher exposure to violence and, in relation to this, their lower sense of security (Light, 1991). They provide care, are the first to respond to questions and everyday problems, and are also responsible for intervening in case of (violent) conflicts.

Contrary to our expectations, employees who work with adjudicated inmates did not show higher exposure to violence than those who work also or solely with inmates awaiting trial or deportation. Instead, staff working with not yet adjudicated inmates were more often victimized and observed violence between inmates more often. These findings differ from results from the U.S. prison system, where violence in prisons is more frequent (James \& Glaze, 2006). But, results are in line with findings from the Spanish prison system, were being on remand was found to be a risk factor for prison violence (Arbach-Lucioni et al., 2012). For Switzerland, explanations may be derived, first, from the fact that several larger institutions, where pre-trial detention is applied-those located in the larger cities - have been moderately to heavily overcrowded over the last years, some up to factors 2 to 3 . Second, upon arrest, most pre-trail detainees suffer from stress and incertitude and are kept in solitary confinement to prevent collusion. Third, staff members generally have only fragmentary information on the personal history and behavior of detainees. These situations together may contribute to greater overall tension and increase the likelihood of violence both between inmates and between inmates and staff.

Staff working solely with female inmates reported to have observed violence between inmates more often compared to staff working with male inmates. This result is in contrast to the study of Harer and Langan (2008) in the U.S. prison system. They found more and more serious violence in male prisons. It also contradicts Wolff et al. 2007, who found no difference in the violence rate in male and female prisons. However, the result is in line with another study of the authors of this paper. Based on official misconduct data in the Swiss prison system, this study equally revealed a higher rate of violence in female prisons in Switzerland (Isenhardt, in press). We can only speculate about the reasons for the 
difference between the results from the Swiss prison system and other prison systems. One reason could be that in Swiss female prisons - maybe also due a gendered practice of Swiss penal courts - the population of inmates arrested for serious violence is higher than in Swiss male prisons and higher than in U.S. female prisons. Prior violence could be a risk factor for prison violence in Switzerland, even though in general previous findings on the importance of violent conviction for violence offense are mixed (Arbach-Lucioni et al., 2012; Steiner \& Wooldredge, 2008; Kuanliang \& Sorensen, 2008). However, Harer and Langan (2001) found a slightly bigger effect of violent history on prison violence for female inmates.

The comparison of the direct and indirect effects for correctional officers and staff who are working with inmates under the age of 25 gave another hint about the importance of violence and sense of security in the emergence of correctional staff burnout. In general, both groups had a lower level of exhaustion and disengagement, but when mediated by experienced and especially by observed violence, the effect is opposite. In indirect form, this reveals a higher risk of burnout for those working with younger inmates and as frontline correctional officers.

The results of the present study should be considered in light of several potential limitations. A first concern relates to the cross-sectional nature of the study. Because all data were collected simultaneously at the same time point, the causal sequence of the variables cannot be unambiguously determined. Both forms of violence are retrospective measures and refer to the six-month period before the study. Although this allows us to introduce a temporal element in the analysis, we cannot be sure that sense of security truly mediates the relationship between violence and burnout. Ideally, sense of security and burnout should be measured on different time points (Maxwell \& Cole, 2007).

However, results of the present study are in line with prior research and show a strong support for the theoretical foundation (Janoff-Bulman \& Hanson Frieze, 1983). Therefore, it can be assumed that our results which support a mediating role of sense of security are valid. Second, both victimization measures could be biased due to their retrospective measurement, which can suffer from bias due to memory gaps (Robinson \& Clore, 2002; Sato \& Kawahara, 2011). Respondents could have had problems remembering and rating exactly how often they had experienced or observed violence during 
the previous six months. In addition, victimization that happened before the six-month period but could still affect sense of security or burnout was not assessed. A second measure to assess whether an employee has been victimized at any time point of her or his career should probably have been included in the analysis in order to control for this currently unobserved long-term effect of victimization.

Third, violence between staff as an important source of job stress could not be included, even though it has been found in some studies to have a bigger impact compared to victimization by inmates and play an important role (e.g., Kunst et al., 2008). Therefore, an important part is missing while studying violence in the workplace. Due to this and to the specific relationship between staff and inmates in corrections, which is characterized by a great imbalance, our results do apply to correctional contexts or contexts, where employees are equally exposed to violent acts of their clients, such as in special schools, health care settings, or asylums (LeBlanc \& Kelloway, 2002; Rasmussen et al., 2013). It is recommended that future studies should consider these aspects and adopt appropriate measures. In addition, potential other mediating or moderating factors in the link between victimization and negative outcomes, such as the potential buffering effect of social support (e.g. Kunst et al., 2008), a positive working atmosphere or various personality variables (e.g. Cartwright \& Cooper, 1996) should be further studied. Also other factors, like general job satisfaction (Galián-Muñoz, Ruiz-Hernández, Llor-Esteban, López-García, 2014) or quality of staff-inmate interactions could play a role.

\section{Conclusion}

Notwithstanding these limitations, our research adds to the knowledge on violence in the corrections field and its negative outcomes. Used with some caution, findings may contribute to the literature on the consequences of workplace violence in general, and, in particular, to the literature about workplace violence in social service occupations. We tested a model which examined the role of sense of security in the relationship between violence and correctional staff burnout in Swiss corrections, and our results show that victimization and witnessing violence between inmates negatively affects the personal sense of security and increases correctional staff burnout. In addition, gender and job characteristics proved to be important. This is especially true for staff members working as correctional officers and employees working with inmates in pre-trial detention and inmates under the age of 25 who 
reported a greater exposure to violence and a lower sense of security.

Several practical implications may be derived from these findings. The strong effect from sense of security on both burnout subscales, exhaustion and disengagement, should convince prison governors and other competent authorities of the correctional system of the importance of improving individual sense of security in order to prevent burnout and its negative consequences. This is especially true for the case of experienced or observed violence, even though this study has shown that victimization does not lead in every case to a reduction of personal feelings of security. But mainly employees with frequent inmate contact are affected. Measures taken by the institution intended to reduce insecurity and provide support in coping with the victimization experience must therefore be geared toward this group of staff members.

Furthermore, our study provides indications that not only serious forms of assault have an impact on correctional staff burnout; although, due to the small number of cases in this study, we were not able to distinguish between different forms of victimization, the overrepresentation of less serious forms of assaults and verbal forms of victimization support this conclusion. Thus, attention should also be paid to the "daily grind" (Bowker, 1980) such as the ordinary forms of violence like insults and intimidation. They are very common in correctional facilities and (too) often ignored. 

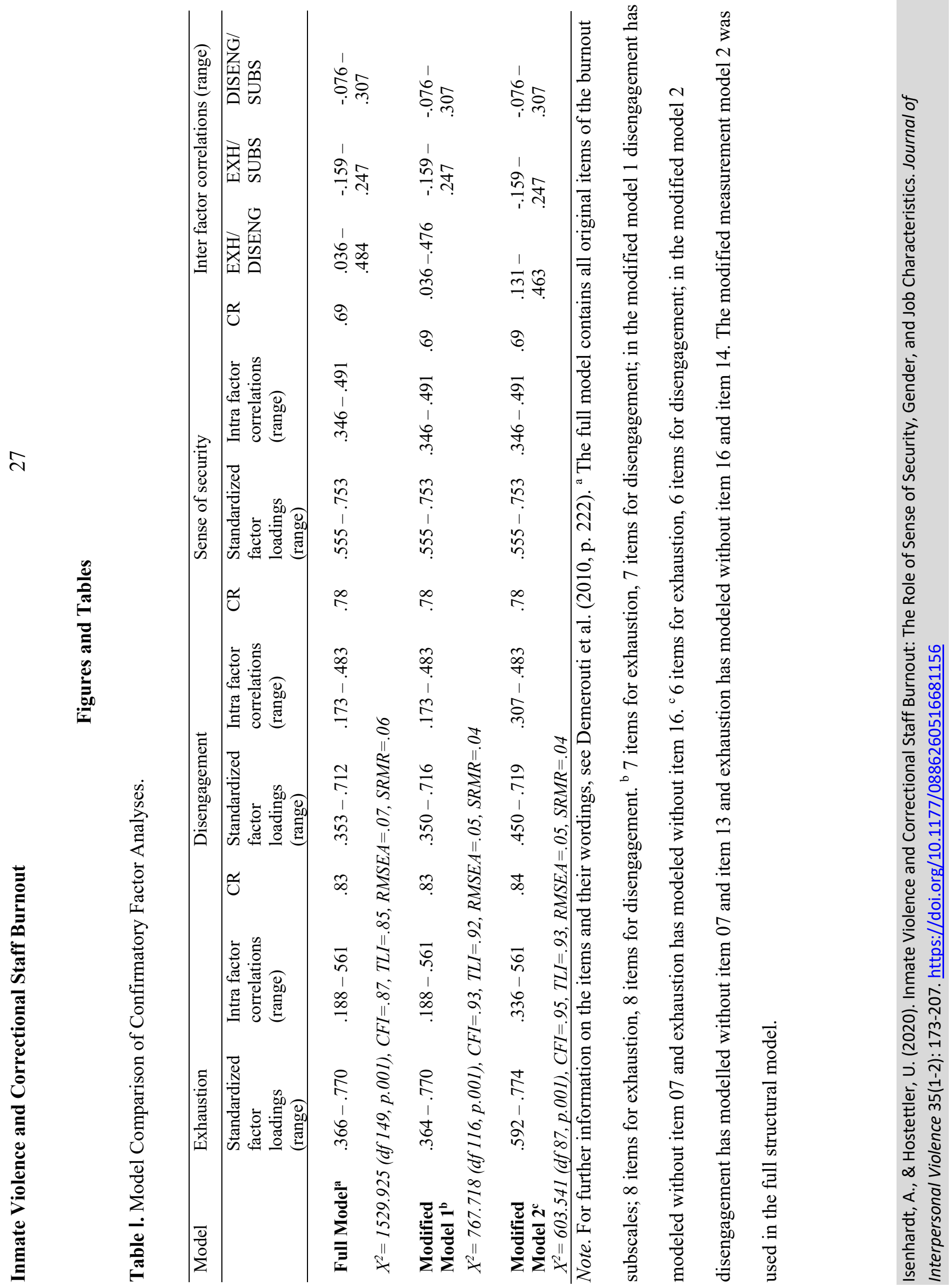
Table 2. Frequency of Experienced and Observed Violence Reported by Correctional Staff in Switzerland.

\begin{tabular}{lcccc}
\hline Form of violence & $\begin{array}{l}\text { Once in 6 month } \\
\text { up to once per } \\
\text { month }\end{array}$ & $\begin{array}{l}\text { Couple of times } \\
\text { per month }\end{array}$ & $\begin{array}{l}\text { Once per } \\
\text { Week }\end{array}$ & $\mathrm{N}$ \\
\hline $\begin{array}{l}\text { Experienced } \\
\text { Insult }\end{array}$ & $59(3.0 \%)$ & $50(2.5 \%)$ & $0(0 \%)$ & 1,958 \\
Intimidation & $28(1.4 \%)$ & $23(1.2 \%)$ & $0(0 \%)$ & 1,963 \\
Grabbed or held & $10(0.5 \%)$ & $0(0 \%)$ & $0(0 \%)$ & 1,967 \\
Assault & $3(0.2 \%)$ & $0(0 \%)$ & $0(0 \%)$ & 1,976 \\
Observed & & & & \\
Verbal & $123(6.1 \%)$ & $100(5.0 \%)$ & $26(1.3 \%)$ & 2,006 \\
Assault without injury & $36(1.8 \%)$ & $21(1.0 \%)$ & $0(0 \%)$ & 2,004 \\
Assault with injury & $13(0.6 \%)$ & $5(0.3 \%)$ & $0(0 \%)$ & 2,002 \\
Sexual assault & $1(0.1 \%)$ & $0(0 \%)$ & $1(0.1 \%)$ & 1,988 \\
Assault with weapon & $1(0.1 \%)$ & $0(0 \%)$ & $0(0 \%)$ & 1,999 \\
\hline
\end{tabular}

Note. Percentages refer to valid cases. All other cases, which are not displayed belong to the category "never."

The answering categories "couple of times per week" and "daily" have not been chosen. 


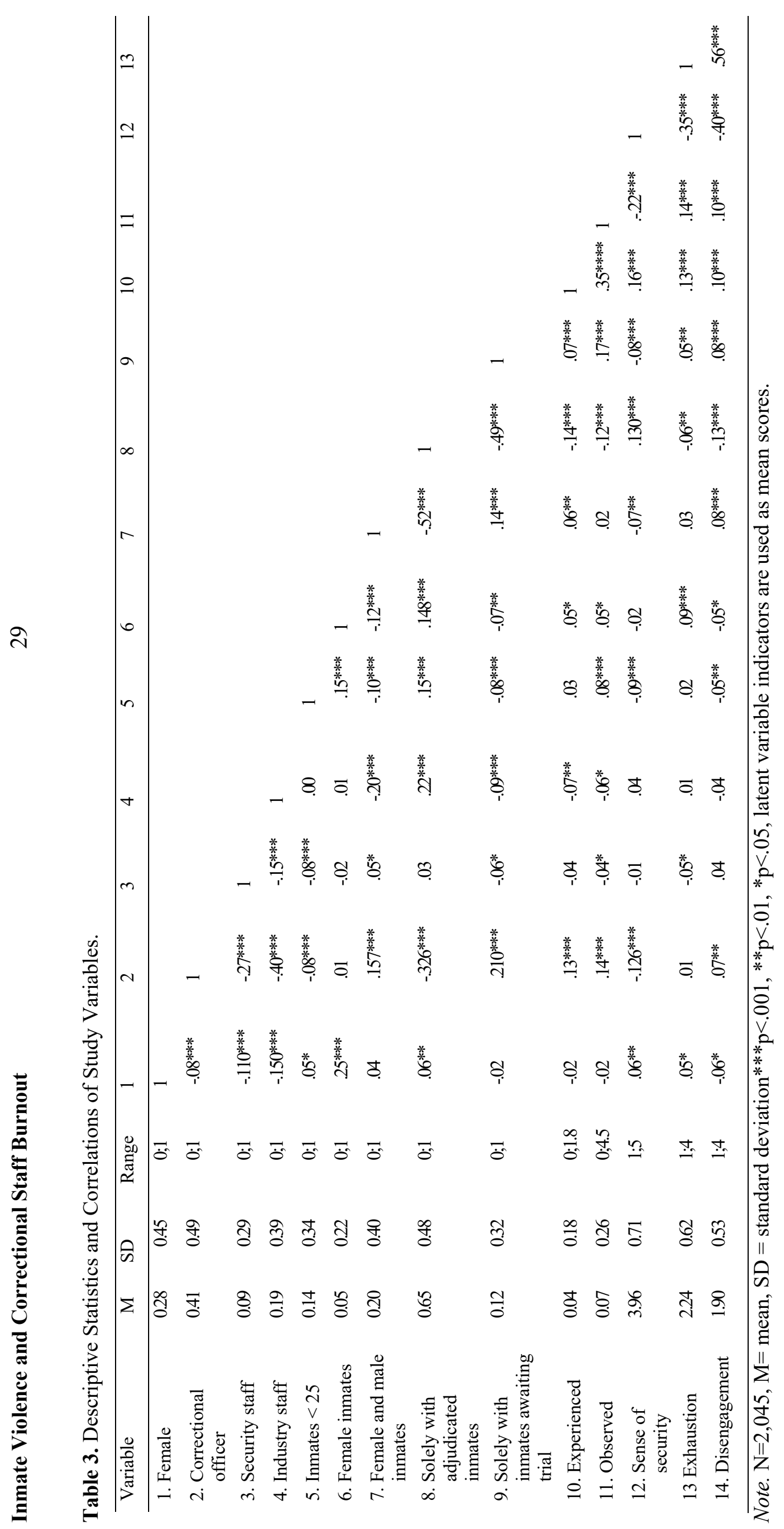




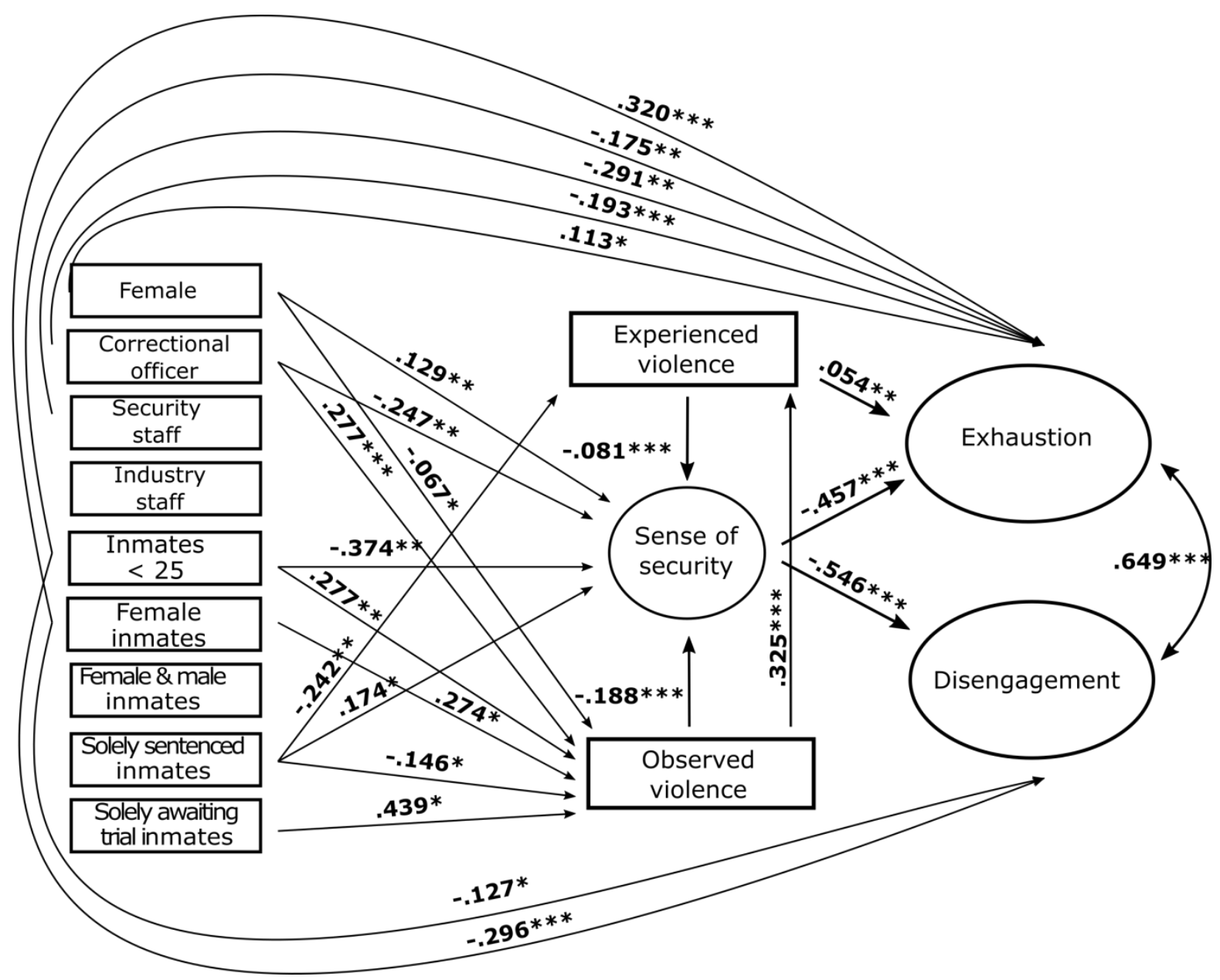

Figure 1. Results of Full Structural Model (Standardized Parameter Estimates).

Note. $\mathrm{N}=1,978$, indicators of the latent variables and non-significant paths are not displayed to increase lucidity. Cluster is institution; standard errors are corrected for non-independence.

${ }^{*} \mathrm{p}<0.10, * * \mathrm{p}<0.03, * * * \mathrm{p}<0.01$ 
Table 4. Indirect and Total Effects of Experienced and Observed Violence on Exhaustion and Disengagement (Standardized Parameter Estimates).

\begin{tabular}{|c|c|c|c|c|c|}
\hline \multirow[t]{2}{*}{ Exogenous variable } & \multirow[t]{2}{*}{ Endogenous variable } & \multicolumn{2}{|c|}{ Total effect } & \multicolumn{2}{|c|}{ Indirect effect } \\
\hline & & $\beta$ & $\mathrm{p}$ & $\beta$ & $\mathrm{P}$ \\
\hline Experienced violence & Exhaustion & .091 & .003 & & \\
\hline Via SOS & & & & .037 & .004 \\
\hline Experienced violence & Disengagement & .074 & .004 & & \\
\hline Via SOS & & & & .044 & .003 \\
\hline Observed violence & Exhaustion & .142 & .001 & & \\
\hline Via SOS & & & & .086 & .001 \\
\hline Via EV & & & & .017 & .051 \\
\hline Via EV and SOS & & & & .012 & .028 \\
\hline Observed violence & Disengagement & .108 & .001 & & \\
\hline Via SOS & & & & .102 & .001 \\
\hline Via EV & & & & .010 & .252 \\
\hline Via EV and SOS & & & & .014 & .021 \\
\hline
\end{tabular}

Note. $\mathrm{N}=1,978, \mathrm{SOS}=$ Sense of security, $\mathrm{EV}=$ Experienced violence 
Table 5. Total, Total Indirect and Specific Indirect Effects of Gender and Job Characteristic

Differences on Sense of Security, Exhaustion and Disengagement (Standardized Parameter

Estimates).

\begin{tabular}{|c|c|c|c|c|c|c|c|}
\hline \multirow[t]{2}{*}{ Exogenous variable } & \multirow[t]{2}{*}{$\begin{array}{l}\text { Endogenous } \\
\text { variable }\end{array}$} & \multicolumn{2}{|c|}{ Total effect } & \multicolumn{2}{|c|}{$\begin{array}{l}\text { Total indirect } \\
\text { effect }\end{array}$} & \multicolumn{2}{|c|}{$\begin{array}{l}\text { Specific } \\
\text { indirect effect }\end{array}$} \\
\hline & & B & $\mathrm{p}$ & $\beta$ & $\mathrm{P}$ & $\beta$ & $\mathrm{p}$ \\
\hline Female & SOS & .147 & .009 & .018 & .021 & & \\
\hline Via $O V$ & & & & & & .013 & .045 \\
\hline Female & EXH & .040 & .527 & -.073 & .009 & & \\
\hline Via SOS & & & & & & -.059 & .033 \\
\hline Via $O V$ and $S O S$ & & & & & & -.006 & .052 \\
\hline Female & DISENG & -.123 & .040 & -.081 & .012 & & \\
\hline Via SOS & & & & & & -.070 & .030 \\
\hline Via $O V$ and $S O S$ & & & & & & -.007 & .044 \\
\hline Correctional officer & SOS & -.295 & .001 & -.048 & .001 & & \\
\hline $\mathrm{Via} O \mathrm{OV}$ & & & & & & -.035 & .001 \\
\hline Via $O V$ and $E V$ & & & & & & -.005 & .054 \\
\hline Correctional officer & EXH & -.045 & .509 & .148 & .001 & & \\
\hline Via SOS & & & & & & .113 & .002 \\
\hline Via $O V$ and $S O S$ & & & & & & .016 & .001 \\
\hline $\begin{array}{l}\text { Via OV, EV and } \\
\text { SOS }\end{array}$ & & & & & & .002 & .063 \\
\hline Correctional officer & DISENG & .083 & .189 & .162 & .001 & & \\
\hline Via SOS & & & & & & .135 & .002 \\
\hline Via $O V$ and $S O S$ & & & & & & .019 & .001 \\
\hline $\begin{array}{l}\text { Via OV, EV and } \\
\text { SOS }\end{array}$ & & & & & & .003 & .051 \\
\hline Inmates age $<25$ & SOS & -.436 & .005 & -.062 & .027 & & \\
\hline Via $O V$ & & & & & & -.052 & .034 \\
\hline Via $O V$ and $E V$ & & & & & & -.007 & .042 \\
\hline Inmates age $<25$ & EXH & .038 & .573 & .213 & .003 & & \\
\hline Via SOS & & & & & & .171 & .008 \\
\hline Via $O V$ and SOS & & & & & & .024 & .030 \\
\hline Via $O V$ and $E V$ & & & & & & .005 & .070 \\
\hline $\begin{array}{l}\text { Via OV, EV and } \\
\text { SOS }\end{array}$ & & & & & & .003 & .043 \\
\hline Inmates age $<25$ & DISENG & -.060 & .519 & .236 & .004 & & \\
\hline Via SOS & & & & & & .204 & .008 \\
\hline Via $O V$ and $S O S$ & & & & & & .028 & .035 \\
\hline $\begin{array}{l}\text { Via OV, EV and } \\
\text { SOS }\end{array}$ & & & & & & .004 & .038 \\
\hline Female inmates & SOS & -.162 & .268 & -.076 & .082 & & \\
\hline Via OV & & & & & & -.051 & .094 \\
\hline Via OV and EV & & & & & & -.007 & .072 \\
\hline $\begin{array}{l}\text { Solely with } \\
\text { adjudicated prisoners }\end{array}$ & SOS & .225 & .047 & .051 & .074 & & \\
\hline Via EV & & & & & & .020 & .090 \\
\hline Via OV & & & & & & .027 & .078 \\
\hline
\end{tabular}

Isenhardt, A., \& Hostettler, U. (2020). Inmate Violence and Correctional Staff Burnout: The Role of Sense of Security, Gender, and Job Characteristics. Journal of Interpersonal Violence 35(1-2): 173-207. 


\begin{tabular}{|c|c|c|c|c|c|c|c|}
\hline $\begin{array}{l}\text { Solely with } \\
\text { adjudicated prisoners }\end{array}$ & EXH & -.148 & .123 & -.122 & .045 & & \\
\hline Via SOS & & & & & & -.080 & .097 \\
\hline Via OV and SOS & & & & & & -.013 & .084 \\
\hline $\begin{array}{l}\text { Solely with } \\
\text { adjudicated prisoners }\end{array}$ & DISENG & -.254 & .007 & -.129 & .047 & & \\
\hline Via SOS & & & & & & -.095 & .097 \\
\hline Via EV and SOS & & & & & & -.011 & .092 \\
\hline Via $O V$ and SOS & & & & & & -.015 & .076 \\
\hline $\begin{array}{l}\text { Solely with inmates } \\
\text { awaiting trial }\end{array}$ & SOS & -.078 & .593 & -.082 & .082 & & \\
\hline Via $O V$ & & & & & & -.082 & .035 \\
\hline
\end{tabular}

Note. $\mathrm{N}=1,978, \mathrm{SOS}=$ Sense of security, $\mathrm{EXH}=$ Exhaustion, $\mathrm{DISENG}=$ Disengagement, $\mathrm{EV}=$

Experienced violence, $\mathrm{OV}=$ observed violence; only significant $(\mathrm{p}<.10)$ indirect effects are displayed.

\section{Notes}

1. Because of Switzerland's federal organization, the provision, organization, and management of correctional facilities in Switzerland is the sole responsibility of the 26 Swiss cantons. In addition, Swiss correctional facilities are characterized by a high degree of autonomy with regard to internal decision-making and management (Baechtold, Weber, \& Hostettler, 2016).

2. Also on the paper-and-pencil questionnaire and in the prior notifications this information was provided and in all facilities the study, its purpose and its voluntariness were pre-announced approximately one week before the questionnaires were distributed.

3. Within these specialized homes, inmates work outside and spend only the night under supervision. The aim of this is to facilitate and support gradual reintegration into society.

4. $2 \%$ of the participants did not mention the security level of their unit. Within this study the influence of unit security level on staff exposure to violence and sense of security has also been tested in a former model but has not shown any significant effect. Therefore it has been dropped from further analyses.

5. Item 8 , which is modelled as indicator of exhaustion also shows high correlations with several items of the disengagement scale (up to $\mathrm{r}=.463$, see table 3 ) and removing this item would probably lead to a further increase of model fit and a reduction of the upper bound of inter factor item correlations. However, item 8 catches a central aspect of exhaustion and has with .774 the highest factor loading on exhaustion. Thus, item 8 remained within the model. 
6 In some bigger facilities intercantonal placements of inmates are performed. But still, even if these institutions mainly perform one kind of detentions, many of them have some places for another kind of detention.

7 Working in a unit which houses inmates awaiting deportation has not been coded as separate dummy variable, because only a very small number of employees worked solely with these inmates. Mostly they work with inmates awaiting deportation and inmates awaiting trial.

\section{References}

Arbach-Lucioni, K., Martinez-García, M., \& Andrés-Pueyo, A. (2012). Risk factors for violent behavior in prison inmates: A cross-cultural contribution. Criminal Justice and Behavior, 39, $1219-1239$.

Baechtold, A., Weber, J., \& Hostettler, U. (2016). Strafvollzug. Straf- und Massnahmenvollzug an Erwachsenen in der Schweiz. Dritte, vollständig überarbeitete und erweiterte Auflage. Bern: Stämpfli Verlag.

Bagozzi, R. P., \& Yi, Y. (1988). On the evaluation of structural equation models. Journal of the Academy of Marketing Science, 16, 74-94.

Barling, J., Rogers, A. G., \& Kelloway, E. K. (2001). Behind closed doors: In-home workers experience of sexual harassment and workplace violence. Journal of Occupational Health Psychology, 6, 255-269.

Beck, A. J., Berzofsky, M., Caspar, R., \& Krebs, C. (2013). Sexual victimization in prisons and jails reported by inmates, 2011-12. Retrieved from http://www.bjs.gov/content/pub/pdf/svpjri1112.pdf.

Blevins, K. R., Cullen, F. T., Frank, J., Sundt, J. L., \& Holmes, S. T. (2006). Stress and satisfaction among juvenile correctional workers. Journal of Offender Rehabilitation, 44, 55-79.

Boudoukha, A. H., Altintas, E., Rusinek, S., Fantini-Hauwel, C., \& Hautekeete, M. (2013). Inmatesto-staff assaults, PTSD and burnout: Profiles of risk and vulnerability. Journal of Interpersonal Violence, 28, 2332-2350. 
Bourbonnais, R., Jauvin, N., Dussault, J., \& Vézina, M. (2007). Psychosocial work environment, interpersonal violence at work and mental health among correctional officers. International Journal of Law and Psychiatry, 30, 355-368.

Bowker, L. H. (1980). Prison victimization. New York: Elsevier.

Brough, P., \& Williams, J. (2007). Managing occupational stress in a high-risk industry: Measuring the job demands of correctional officers. Criminal Justice and Behavior, 34, 555-567.

Camp, S. D., Gaes, G. G., Langan, N. P., \& Saylor, W. G. (2003). The influence of prisons on inmate misconduct: A multilevel investigation. Justice Quarterly, 20, 501-533.

Cartwright, S., \& Cooper, C. L. (1996). Coping in occupational settings. In M. Zeidner \& N. S. Endler (Eds.), Handbook of coping. Theory, research, applications (pp. 202-220). New York: John Wiley.

Chappel, D., \& Di Martino, V. (2006). Violence at work (3rd edition). Geneva: ILO.

Clemmer, D. (1940). The prison community. New York: Holt, Rinehart and Winston.

Demerouti, E., \& Bakker, A. B. (2008). The Oldenbourg Burnout Inventory: A good alternative to measure burnout and engagement. In J. R. Halbesleben (Ed.), Handbook of stress and burnout in healthcare. New York: Nova Science.

Demerouti, E., Mostert, K., \& Bakker, A. B. (2010). Burnout and work engagement: A thorough investigation of the independency of both constructs. Journal of Occupational Health Psychology, 15, 209-222.

Demerouti, E., Bakker, A. B., Vardakou, I., \& Kantas, A. (2003). The convergent validity of two burnout instruments: A multitrait-multimethod analysis. European Journal of Psychological Assessment, 18, 296-307.

Dowden, C., \& Tellier, C. (2004). Predicting work-related stress in correctional officers: A metaanalysis. Journal of Criminal Justice, 32, 31-47.

Finn, P. (1998). Correctional officer stress: A cause for concern and additional help. Federal Probation, 62, 65-74.

Finney, C., Stergiopoulos, E., Hensel, J., Bonato, S., \& Dewa, C. S. (2013). Organizational stressors 
associated with job stress and burnout in correctional officers: a systematic review. $B M C$ Public Health, 82(Article 82). Retrieved from http://www.biomedcentral.com/1471$2458 / 13 / 82$.

Galián-Muñoz, I., Ruiz-Hernández, J. A., Llor-Esteban, B., \& López-García, C. (2014). User violence and nursing staff burnout: The modulating role of job satisfaction. Journal of Interpersonal Violence, Online first, DOI: 0.1177/0886260514555367, 1-14.

Gordon, J. A., Moriarty, L. J., \& Grant, P. H. (2003). Juvenile correctional officer' perceived fear and risk of victimization: Examining individual and collective levels of victimization in two juvenile correctional centers in Virginia. Criminal Justice and Behavior, 30, 62-84.

Griffin, M. L. (2001). Job satisfaction among detention officers: Assessing the relative contribution of organizational climate variables. Journal of Criminal Justice, 29, 219-232.

Hale, C. (1996). Fear of crime: A review of the literature. International Review of Victimology, 4, 79150.

Harer, M., \& Langan, N. P. (2001). Gender differences in predictors of prison violence: Assessing the predictive validity of a risk classification system. Crime and Delinquency, 47, 513-536.

Homburg, C., \& Giering, A. (1996). Konzeptualisierung und Operationalisierung komplexer Konstrukte: Ein Leitfaden für die Marketingforschung. Marketing: Zeitschrift für Forschung und Praxis, 18, 5-24.

Hostettler, U., \& Isenhardt, A. (2015). La situation des collaborateurs des établissements d'exécution des peines et des mesures en Suisse. Principaux résultats de l'enquête nationale. Informations sur l'exécution des peines et mesures - bulletin info, 40(1), 16-20.

Hox, J. J. (2010). Multilevel analysis: Techniques and applications (2nd ed.). New York, NY:

Routledge.

Hu, L.-T., \& Bentler, P. M. (1999). Cutoff criteria for fit indexes in covariance structure analysis: Conventional criteria versus new alternatives. Structural Equation Modelling, 6, 1-55.

Irwin, J., \& Cressey, D. R. (1962). Thieves, convicts and the inmate culture. Social Problems, 10, $142-155$. 
Isenhardt, A. (in press). Disziplinarverstösse im schweizerischen Straf- und Massnahmenvollzug: Ergebnisse einer Erhebung zur Situation in den Anstalten. Schweizerische Zeitschrift für Kriminologie, 15.

Isenhardt, A., Hostettler, U., \& Young, C. (2014). Arbeiten im schweizerischen Justizvollzug. Ergebnisse einer Befragung zur Situation des Personals. KJS. Bern: Stämpfli Verlag. Isenhardt, A., Young, C., \& Hostettler, U. (2016). Die Gesundheit des Personals im Schweizer Justizvollzug - Unterschiede zwischen Betreuungspersonal und Spezialdiensten. Bewährungshilfe - Soziales - Strafrecht - Kriminologie, 63, 34-49.

James, D. J., \& Glaze, L. E. (2006). Mental health problems of prison and jail inmates. Retrieved from: http://www.bjs.gov/content/pub/pdf/mpji.pdf.

Janoff-Bulman, R., \& Hanson Frieze, I. (1983). A theoretical perspective for understanding reactions to victimization. Journal of Social Issues, 39, 1-17.

Kuanliang, A., \& Sorensen, J. (2008). Predictors of self-reported prison misconduct. Criminal Justice Studies, 21, 27-35.

Kuanliang, A., Sorensen, J., \& Cunningham, M. D. (2008). Juvenile inmates in an adult prison system: Rates of disciplinary misconduct and violence. Criminal Justice and Behavior, 35, $1186-1201$.

Kunst, M., Schweizer, S., Bogaerts, S., \& van der Knaap, L.M. (2008). Aggression and violence, posttraumatic stress, and absenteeism among employees in penitentiaries. Den Haag: Boom Juridische Uitgevers.

Lahm, K. F. (2009). Educational participation and inmate misconduct. Journal of Offender Rehabilitation, 48, 37-52.

Lai, Y.-L., Wang, H.-M., \& Kellar, M. (2012). Workplace violence in correctional institutions in Taiwan: A study of correctional officers' perceptions. International Journal of Comparative and Applied Criminal Justice, 36, 1-23.

Lambert, E. G., Hogan, N. L., \& Altheimer, I. (2010a). The association between work-family conflict and job burnout among correctional staff: A preliminary study. American Journal of Criminal 
Justice, 35, 37-55.

Lambert, E. G., Hogan, N. L., \& Altheimer, I. (2010b). An exploratory examination of the consequences of burnout in terms of life satisfaction, turnover intent, and absenteeism among private correctional staff. The Prison Journal, 90, 94-114.

Lambert, E. G., Hogan, N. L., \& Griffin, M. L. (2007). The impact of distributive and procedural justice on correctional staff job stress, job satisfaction, and organizational commitment. Journal of Criminal Justice, 35, 644-656.

LeBlanc, M. M., \& Kelloway, E. K. (2002). Predictors and outcomes of workplace violence and aggression. Journal of Applied Psychology, 87, 444-453.

Lehmann, A., \& Greve, W. (2006). Justizvollzug als Profession: Herausforderungen eines besonderen Tätigkeitsbereichs. Baden-Baden: Nomos.

Light, S. C. (1991). Assaults on prison officers: Interactional themes. Justice Quarterly, 8, 243-262.

Losavio, S. T., Cohen, L. H., Laurenceau, J.-P., Dasch, K. B., Parrish, B. P., \& Park, C. L. (2011). Reports of stress-related growth from daily negative events. Journal of Social and Clinical Psychology, 30, 760-785.

Maslach, C. (2003). Job burnout: New directions in research and intervention. Current Directions. Psychological Science, 12, 189-192.

Maslach, C., \& Jackson, S. E. (1981). The measurement of experienced burnout. Journal of Occupational Behavior, 2, 99-113.

Maxwell, S. E., \& Cole, D. A. (2007). Bias in cross-sectional analyses of longitudinal mediation. Psychological Methods, 12, 23-44.

Mumola, C. J. (2005). Suicide and homicide in state prisons and local jails. Retrieved from: http://www.bjs.gov/content/pub/pdf/shsplj.pdf.

Muthén, L. K., \& Muthén, B. O. (2015). Mplus users guide (7th edition). Los Angeles, CA: Muthén \& Muthén.

Rasmussen, C. A., Hogh, A., \& Andersen, L. P. (2013). Threats and physical violence in the workplace: A comparative study of four areas of human service work. Journal of 
Interpersonal Violence, 28, 2749-2769.

Raykov, T. (1997). Estimation of composite reliability for congeneric measures. Applied Psychological Measurement, 21, 173-184.

Raykov, T. (2012). Scale construction and development using structural equation modeling. In R. H. Hoyle (Ed.), Handbook of structural equation modeling (pp. 472-492). New York: Guilford.

Robinson, M. D., \& Clore, G. L. (2002). Episodic and semantic knowledge in emotional self-report: Evidence for two judgment processes. Journal of Personality and Social Psychology, 83, $198-215$.

Rogers, K.-A., \& Kelloway, E. K. (1997). Violence at work: Personal and organizational outcomes. Journal of Occupational Health Psychology, 2, 63-71.

Sato, H., \& Kawahara, J.-I. (2011). Selective bias in retrospective self-reports of negative mood states. Anxiety, Stress, \& Coping, 24, 359-367.

Schat, Aaron C. H., \& Kelloway, E. K. (2000). Effects of perceived control on the outcomes of workplace aggression and violence. Journal of Occupational Health Psychology, 5, 386-402.

Schat, Aaron C. H., \& Kelloway, E. K. (2003). Reducing the adverse consequences of workplace aggression and violence: The buffering effects of organizational support. Journal of Occupational Health Psychology, 8, 110-122.

Schaufeli, W. B., \& Peeters, Maria C. W. (2000). Job stress and burnout among correctional officers: A literature review. International Journal of Stress Management, 7, 19-48.

Snacken, S. (2005). Forms of violence and regimes in prison: Report of research in Belgian prisons. In A. Liebling \& S. Maruna (Eds.), The effects of imprisonment (pp. 306-339). Abingdon: Willan Publishing.

Spector, P. E., Coulter, M. L., Stockwell, H. G., \& Matz, M. W. (2007). Perceived violence climate: A new construct and its relationship to workplace physical violence and verbal aggression, and their potential consequences. Work and Stress, 21, 117-130.

Spinaris, C. G., Denhof, M. D., \& Kellaway, J. A. (2012). Posttraumatic stress disorder in United States corrections professionals: Prevalence and impact on health and functioning. Retrieved 
from http://desertwaters.com/wp-content/uploads/2013/09/PTSD_Prev_in_Corrections_0903-131.pdf.

Steiner, B., \& Wooldredge, J. (2008). Inmate versus environmental effects on prison rule violations. Criminal Justice and Behavior, 35, 438-456.

Steiner, B., \& Wooldredge, J. (2015). Individual and environmental sources of work stress among prison officers. Criminal Justice and Behavior, 42, 800-818.

Sykes, G. M. (1958). The society of captives. A study of a maximum security prison. Princeton: Princeton Univ. Press.

Toch, H. (1992). Living in prison: The ecology of survival (2nd edition). Washington, DC: American Psychological Association.

Wolff, N., Blitz, C. L., Shi, J., Siegel, J., \& Bachman, R. (2007). Physical Violence Inside Prisons. Criminal Justice and Behavior, 34, 588-599.

Wolff, N., \& Shi, J. (2009). Feelings of safety among male inmates. The safety paradox. Criminal Justice Review, 34, 404-427.

Wolff, N., \& Shi, J. (2011). Patterns of victimization and feelings of safety inside prison: The experience of male and female inmates. Crime and Delinquency, 57, 29-55.

Wooldredge, J., \& Steiner, B. (2015). A macro-level perspective on prison inmate deviance. Punishment and Society, 17, 230-257. 